\title{
SMOKING PATTERNS IN CROATIA AND COMPARISONS WITH EUROPEAN NATIONS
}

\author{
Rajeev K. Goel ${ }^{1}$, Jelena Budak ${ }^{2}$ \\ ${ }^{1}$ Department of Economics, Illinois State University, USA \\ ${ }^{2}$ Institute of Economics, Zagreb
}

\section{SUMMARY}

In recent years, tobacco use and its control have become increasingly the focus of attention of policy-makers and researchers due to ill health effects of smoking on both smokers and non-smokers. This paper contributes to a neglected research area by focusing on tobacco use and its regulation in Croatia. In particular, this study uses recent survey information to analyze the tobacco use patterns in Croatia and influence of tobacco campaigns and to compare these patterns to other EU candidate nations and the EU as a whole.

Overall the results show that in some aspects of tobacco use and regulation Croatia fares better than other European countries, while in other aspects it is somewhat lagging. For instance, on the positive side, more Croat smokers and ex-smokers were exposed to anti-smoking campaigns than smokers in other countries. However, the effectiveness of such exposure is modest in terms of the percentage of smokers who wanted to quit smoking and the relatively low share of population which claims protection from second-hand smoke. Croatia also has to further strengthen the country's compliance with international tobacco control mandates in terms of enforcement of existing tobacco consumption restrictions. Besides shedding light on the effectiveness of tobacco control policies, the findings of this study have some implications for Croatia's accession to the EU.

Key words: smoking, cigarettes, second-hand smoke, tobacco control, Croatia

Address for correspondence: J. Budak, Institute of Economics, Zagreb, Trg J. F. Kennedy 7, HR-10000 Zagreb, Croatia. E-mail: jbudak@eizg.hr

\section{INTRODUCTION}

Tobacco control policy has recently increasingly come to the focus of policy-makers worldwide because of the recognized negative effects of tobacco consumption. The health consequences of tobacco use are substantial. For instance, it is estimated that over half a million deaths (15\% of all deaths) in the EU annually are due to tobacco use (Directive 2003/33/EC). In Europe as a whole, tobacco causes more than a million deaths annually. These are substantial negative effects, especially in the case of a malice that is preventable. In the case of Croatia, about a third of the population currently smokes, causing 11,000 deaths per annum (the total population of Croatia is 4.5 million). In response to such revelations, smoking control policy interventions and recommendations have sprouted both at national and cross-national levels (1). The subject of tobacco control has also caught the attention of researchers in recent years. However, besides a handful of primarily developed nations, we lack an adequate understanding of tobacco use and the effectiveness of tobacco control policies in most nations. A notable exception is the collection studies of Jha and Chaloupka (2) and some global estimates of smoking prevalence in the nineties (3). This paper attempts to somewhat address this deficiency by focusing on Croatia. Croatia is taken as an example to see how the overall reforms and adjustment process within EU integration might affect tobacco use and its regulation. Besides, very little research exists on smoking behaviours in Croatia and how they compare with its European counterparts.

In response to findings about the effects of second-hand smoke a number of smoking control initiatives were undertaken. In 1998 the European Union passed a directive to ban tobacco advertising, and other legislative restrictions were imposed to protect public health against the harmful effects of smoking. In May 2003, the 192 members of the World Health Organization (WHO) adopted the Framework Convention on Tobacco Control (FCTC) aimed at curbing tobacco-related deaths and disease. The objective of the FCTC is "to protect present and future generations from the devastating health, social, environmental and economic consequences of tobacco consumption and exposure to tobacco smoke" (4). The Convention requires signatory countries to impose restrictions on tobacco advertising, sponsorship and promotion, establish new labeling and clean indoor air controls and strengthen legislation to clamp down on tobacco smuggling. The intent is to have some uniformity in the strength of tobacco control measures across countries. Croatia signed the WHO Framework Convention on Tobacco Control in June 2004. To date more than 150 nations have ratified the Framework.

The impacts of cross-national policies vary across large and small nations. For Croatia, the design of tobacco control regulations is mostly determined by the various international mandates. One reason for this is the relatively small size of the country (both physically and economically) and another reason is its desire to 
join the European Union (EU). Before Croatian policy-makers can frame polices and garner resources to respond to external smoking-control mandates, they need a good understanding of smoking trends in Croatia and how the country compares with other countries and/or groups of countries. For instance, if smoking prevalence and quit rates are similar in Croatia to those in other nations, then blanket smoking-control policies would work well; otherwise cross-country recommendations would have to be fine-tuned to be effective in the Croatian case.

The purpose of this paper is to provide recent evidence on smoking trends in Croatia and to compare tobacco use in Croatia with other nations in Europe. More broadly, the present research may be seen as a contribution to the literature on tobacco use and its control in individual nations. Specifically, the effectiveness of anti-smoking policy in Croatia is analyzed in this paper using the selected data from a survey conducted in the EU and associated countries in 2005 (5). We compare Croatia with the average of all EU 25 member states and separately for the group of old members (EU15) and new member states since May 2004 (NMS10). A particular research interest was to examine the performance of Croatia compared to the group of candidate countries (CAC) including Croatia (HR), Romania (RO) and Bulgaria (BG). Specifically, Romania and Bulgaria became members of the EU from January 1, 2007, which is ahead of the expected Croatian full membership. We also provide some evidence on the smoking patterns among population subgroups in Croatia. We turn next to a discussion of the findings on tobacco use and anti-tobacco campaigns in Croatia and on comparisons with Croatia's European counterparts.

\section{TOBACCO USE AND REGULATION}

\section{Smoking Prevalence}

The prevalence of smoking captures the percentage of smokers in a country. This has implications for designing policies to combat smoking initiation, such as initiatives to prevent smoking by youth.

The questionnaire survey used in Eurobarometer for Croatia was conducted in November/December 2005 through face-to-face interviews with 1000 persons aged 15 or more. Table 1 shows that smoking prevalence in Croatia is higher than that in EU25. Smoking prevalence in Croatia is slightly above the EU average of $33 \%$ adults smoking.

In Croatia $36 \%$ of persons aged 15 years or more smoke. This figure is higher than the $33 \%$ figure for 1970 from an earlier survey (6). Of the $64 \%$ of non-smokers, $18 \%$ are ex-smokers. The $46 \%$ of Croats who never smoked is at par with EU25 average (47\% of citizens never smoked). The type of tobacco products consumed in Croatia consists entirely of packaged cigarettes. This implies that
Table 1. Smoking prevalence

\begin{tabular}{|l|c|c|c|c|}
\hline Country & $\begin{array}{c}\text { Smoking } \\
\text { prevalence }\end{array}$ & Non-smokers & Ex-smokers & $\begin{array}{c}\text { Never } \\
\text { smoked }\end{array}$ \\
\hline EU25 & $33 \%$ & $68 \%$ & $21 \%$ & $47 \%$ \\
\hline EU15 & $33 \%$ & $68 \%$ & $21 \%$ & $47 \%$ \\
\hline NMS10 & $32 \%$ & $68 \%$ & $17 \%$ & $51 \%$ \\
\hline CAC & $35 \%$ & $65 \%$ & $15 \%$ & $50 \%$ \\
\hline HR & $36 \%$ & $64 \%$ & $18 \%$ & $46 \%$ \\
\hline RO & $31 \%$ & $68 \%$ & $11 \%$ & $57 \%$ \\
\hline BG & $38 \%$ & $62 \%$ & $15 \%$ & $47 \%$ \\
\hline
\end{tabular}

Note: EU 25-European Union Member States; EU15- "old" EU member States; NMS10-"new" EU Member Sates as of May 2004; CAC-EU Candidate Countries (Bulgaria, Croatia, Romania); HR-Croatia; RO-Romania and BG-Bulgaria. Figures might not sum to 100 due to rounding.

Source: Eurobarometer: Attitudes of Europeans Towards Tobacco, EC, 2006

Croat smokers are less likely to substitute other tobacco products for cigarettes when cigarette taxes go up and more likely to purchase cheaper cigarettes available in the gray market.

There seem to be fewer ex-smokers in NMS10 than in the EU15. Further, compared to other candidate nations, Croatia has more ex-smokers, while smoking prevalence and the percentage of non-smokers fall between the corresponding percentages in Romania (68\%) and Bulgaria (62\%). Romania and Bulgaria are countries with the lowest quit rates $(11 \%$ and $15 \%$ of non-smokers, respectively). ${ }^{1}$

\section{Smoking Intensity}

Smoking prevalence or smoking participation tells us about the scope of smoking but does not distinguish between casual and heavy smokers. The health consequences of smoking are particularly going to be severe on heavy smokers; while casual smokers, if not helped to quit smoking, might over time become heavy smokers.

Compared to other nations, Croatia seems to have fewer casual smokers and relatively more heavy smokers (Table 2). There are also fewer occasional smokers in Croatia of all the countries in the comparison group, with the exception of Romania. The share of "occasional smokers" reporting they do not smoke every day (3\% in Croatia) is not encouraging. If this figure is added to smokers who smoke less then 5 cigarettes a day, only $12 \%$ of smokers may be considered as "light" smokers. For this group of smokers it might be easier to quit because they seem to be less addicted to cigarette consumption. On the other hand, $3 \%$ of smokers in Croatia consume more than 35 cigarettes a day, a number that exceeds the corresponding statistic in EU and candidate countries' "heavy smokers" consumption. Thus, appropriate intervention programs to induce heavy Croatian smokers to quit need to be designed. $^{2}$

\footnotetext{
${ }^{1}$ Given appropriate data one could conduct an econometric study of the determinants of smoking prevalence in Croatia. Usual explanatory variables in such studies include smoking prevalence as a function of tax-inclusive cigarette price, income, demographic information (race, gender, education) and some measure of regulation such as advertising bans, etc. Such economic studies for a transition country like Croatia are difficult because of insufficient degrees of freedom (not enough years of data) and the fact that a substantial portion of cigarettes sold in Croatia might be smuggled and/or are sold in the gray market. Hence, an appropriate measure of cigarette price is difficult to determine. Over time some of these problems will take care of themselves enabling more formal analyses.

${ }^{2} \mathrm{An}$ interesting piece of information that one would like to have is regarding what percentage of current smokers had quit smoking in the past and had a relapse. Such information has implications for the design of effective cessation programs. In all fairness though, such detailed information is hard to come by for all nations, not merely those in transition.
} 
Table 2. Cigarettes smoked per day

\begin{tabular}{|l|c|c|c|}
\hline Country & Less than $\mathbf{5}$ & $\mathbf{3 5}$ to $\mathbf{3 9}$ & $\begin{array}{c}\text { Do not smoke } \\
\text { every day }\end{array}$ \\
\hline EU25 & $11 \%$ & $1 \%$ & $4 \%$ \\
\hline EU15 & $9 \%$ & $1 \%$ & $5 \%$ \\
\hline NMS10 & $11 \%$ & $2 \%$ & $5 \%$ \\
\hline CAC & $11 \%$ & $1 \%$ & $4 \%$ \\
\hline HR & $9 \%$ & $3 \%$ & $3 \%$ \\
\hline RO & $10 \%$ & $0 \%$ & $3 \%$ \\
\hline BG & $14 \%$ & $2 \%$ & $5 \%$ \\
\hline
\end{tabular}

Source: Eurobarometer: Attitudes of Europeans Towards Tobacco, EC, 2006.

\section{Second-hand Smoke}

In recent years, the rights of non-smokers have come to the forefront as the dangers of second-hand smoke have become known. This has prompted governments to impose additional smoking restrictions, particularly in the form of territorial restrictions, including workplace and public place smoking bans. These policies increase the indirect costs of smoking by making smoking more inconvenient. Further, the direct costs of smoking might also go up when fines are imposed for smoking in restricted areas. Table 3 presents survey results regarding attitudes towards inconveniences caused by second-hand smoke.

If the non-smoking territorial restrictions are not fully applied, smoking might remain widespread but it may not bother people. An explanation of this second option might be found in the low awareness of harmful effects of passive smoking. The social mindset that smoking could bother other people seems not as prevalent in Bulgaria compared to Romania and the NMS10 average.

In Croatia, close to the EU25 average, $10 \%$ of respondents would always ask a smoker to not smoke near them. However, another $57 \%$ of Croatian people would never ask a smoker to stop smoking because it bothered them. It seems that in a country where smoking restrictions in public places are not strictly enforced, people are likely to feel somewhat uncomfortable to ask for the protection of their personal health.

The "culture" of smoking further reveals the sources of this habit. The second-hand smoke exposure is increased if there is propensity to smoke at home. A majority of smokers smoke at home (Table 4). Croatia is at the top of the surveyed countries with $87 \%$ of smokers who smoke at home. It is a rather high percentage compared to that in EU25 countries (78\%). One may note that in all candidate countries, there are higher percentages of smokers who smoke at home, especially in Romania (91\%). Smoking at home is particularly threatening as children are exposed to secondhand smoke. Since there are no efficient legal restrictions to be applied in private areas, other tobacco control measures should be imposed to raise anti-smoking awareness.

\section{Smoking Attitudes among Subgroups in Croatia}

In Table 5, we provide some evidence on the smoking prevalence and attitudes among two Croatian population subgroups - medical students and youth. ${ }^{3}$ Both smoking participation and smoking prevalence seem higher among medical students (7). Further, gender differences seem more pronounced among the youth (8).

The smoking prevalence among youth seems to be increasing in last decade, after having declined for some time. The smoking prevalence among Zagreb secondary students was $15 \%$ among males and $12 \%$ among females in 1991; while the corresponding figures were $39 \%$ and $20 \%$ in 1973 (6). The propensity towards smoking cessation was greater among medical students, while there was a greater support for geographic smoking bans among the youth. Finally, medical schools in Croatia seemed to do a better job of educating about the health effects of smoking than primary and secondary schools.

\section{Tobacco and Other Products}

Tobacco products are often consumed in combination with other addictive products, notably alcohol. The relationship of cigarettes with other products is important in understanding the effectiveness of policies. If smokers use other products in conjunction with cigarettes or in place of cigarettes, this has implications for how policies are designed to reduce smoking. Economists have studied the relationship between cigarettes and various products. Studies examining the relation of cigarette and alcohol consumption have been done for developed countries, such as the U.S. (9), Canada (10) and Australia (11). The literature also provides evidence of relationship between cigarettes and

Table 3. Attitudes towards second-hand smoke

\begin{tabular}{|l|c|c|c|c|}
\hline \multirow{3}{*}{ Country } & \multicolumn{2}{|c|}{$\begin{array}{c}\text { How often are you bothered by exposure } \\
\text { to tobacco smoke in your daily life? }\end{array}$} & Never & \multicolumn{2}{c|}{$\begin{array}{c}\text { Do you ever ask a smoker not to smoke } \\
\text { near you because it bothers you? }\end{array}$} \\
\cline { 2 - 5 } & Very often & $27 \%$ & $9 \%$ & Never \\
\hline EU25 & $15 \%$ & $30 \%$ & $8 \%$ & $48 \%$ \\
\hline EU15 & $12 \%$ & $23 \%$ & $12 \%$ & $50 \%$ \\
\hline NMS10 & $21 \%$ & $27 \%$ & $10 \%$ & $44 \%$ \\
\hline CAC & $16 \%$ & $29 \%$ & $10 \%$ & $45 \%$ \\
\hline HR & $15 \%$ & $22 \%$ & $12 \%$ & $57 \%$ \\
\hline RO & $20 \%$ & $29 \%$ & $7 \%$ & $36 \%$ \\
\hline BG & $14 \%$ & & & $43 \%$ \\
\hline
\end{tabular}

Source: Eurobarometer: Attitudes of Europeans Towards Tobacco, EC, 2006.

${ }^{3}$ Unfortunately, we do not have relevant data from other countries in Europe to make this table comparable to others in the paper. Nevertheless, Table 5 highlights the qualitative differences across groups. 
Table 4. Smoke at home

\begin{tabular}{|l|c|}
\hline Country & Smokers who smoke at home \\
\hline EU25 & $78 \%$ \\
\hline EU15 & $79 \%$ \\
\hline NMS10 & $76 \%$ \\
\hline CAC & $86 \%$ \\
\hline HR & $87 \%$ \\
\hline RO & $91 \%$ \\
\hline BG & $81 \%$ \\
\hline
\end{tabular}

Source: Eurobarometer: Attitudes of Europeans Towards Tobacco, EC, 2006.

smokeless tobacco $(12,13)$ and cigarettes and marijuana (11). The relationship between cigarettes and other addictive products consumption, however, is still unclear. For instance, the substitution - complementarity relationship between cigarettes and alcohol is unresolved in the literature - some studies have found the two products to be substitutes (9), while others have found them to be complements (11). Thus, given appropriate data, related relationships for Croatia (and other nations) could be determined and effective tobacco control policies framed.

The percentage of smokers who very often combine cigarettes with alcohol drinks is the highest in old member states (EU15) where $26 \%$ of smokers light a cigarette while also consuming an alcohol drink (Table 6). In Croatia and Romania this percentage is considerably lower, $12 \%$ and $11 \%$, respectively. A third of smokers in Croatia never combine cigarettes and alcohol drinks. That attitude of Croatian smokers suggests that for a large share of smokers, cigarettes and alcohol drinks are not complements.

Interestingly, joint consumption of cigarettes with other products including alcohol, medicines and drugs is lower in NMS10 than in EU15. However, the corresponding percentages in both cases are higher than those in Croatia, especially for alcohol and medicines (Table 6). Combining medicines with a smoke reveals that even when people are sick or advised to stop smoking because they are taking prescription drugs, they do not stop smoking. In the whole of EU about $10 \%$ of smokers take medicines jointly with cigarettes. A small percentage of smokers takes cannabis or other drugs while smoking and this is due to the fact that generally people do not take illegal drugs. Fewer Croats seem to be smoking cigarettes in conjunction with other addictive products compared to states in the European Union; although the same is not necessarily true with respect to other candidate nations. ${ }^{4}$

\section{Tobacco Control Legislation}

Due to the impacts of smoking on nonsmokers and the fact that tobacco use has habit forming effects, government intervention is warranted in the production, marketing and use of tobacco products in general. Tobacco control policies may be broadly classified into two categories: price- or tax-based policies on the one hand, and non-price policies on the other hand. The non-price policies run a whole range including advertising restrictions, health education, territorial smoking restrictions, etc. These legislations vary considerably across nations and even across regions in the same country (14). Reviews of the economics
Table 5. Smoking prevalence and smoking attitudes among population subgroups in Croatia

\begin{tabular}{|c|c|c|c|c|c|c|}
\hline Questions & \multicolumn{3}{|c|}{$\begin{array}{c}\text { Medical students, } \\
2005(\%)\end{array}$} & \multicolumn{3}{|c|}{$\begin{array}{l}\text { Youth, } \\
2002(\%)\end{array}$} \\
\hline \multirow{2}{*}{$\begin{array}{l}\text { Have you ever smoked } \\
\text { cigarettes? - Yes }\end{array}$} & \multirow{2}{*}{67.4} & 67.0 & male & \multirow{2}{*}{59.9} & 62.5 & male \\
\hline & & 67.8 & female & & 56.3 & female \\
\hline \multirow{2}{*}{ Currently smoke cigarettes } & \multirow{2}{*}{36.6} & 35.9 & male & \multirow{2}{*}{16.6} & 18.5 & male \\
\hline & & 37.1 & female & & 14.3 & female \\
\hline $\begin{array}{l}\text { Current smokers who } \\
\text { wanted to stop smoking }\end{array}$ & \multicolumn{3}{|l|}{55.2} & \multicolumn{3}{|l|}{49.9} \\
\hline $\begin{array}{l}\text { Thought smoking should be } \\
\text { banned in all public places }\end{array}$ & \multicolumn{3}{|l|}{57.7} & \multicolumn{3}{|l|}{76.8} \\
\hline $\begin{array}{l}\text { Were taught dangers } \\
\text { of smoking at school }\end{array}$ & \multicolumn{3}{|l|}{94.9} & \multicolumn{3}{|l|}{57.4} \\
\hline
\end{tabular}

Note: The survey of medical students was based on 404 third-year medical students in Croatia. Youth survey was based on 5,038 students in Primary 6-8 grades and First Secondary Schools in Croatia in 2002.

Source: Croatia - Medical Students Global Health Professionals Survey (GHPS), Croatia - Global Youth Tobacco Survey (GYTS).

Table 6. Smokers who combine cigarettes with other products

\begin{tabular}{|l|c|c|c|}
\hline Country & With alcohol & With medicines & $\begin{array}{c}\text { With cannabis } \\
\text { or drugs }\end{array}$ \\
\hline EU25 & $23 \%$ & $11 \%$ & $2 \%$ \\
\hline EU15 & $26 \%$ & $11 \%$ & $2 \%$ \\
\hline NMS10 & $19 \%$ & $10 \%$ & $1 \%$ \\
\hline CAC & $15 \%$ & $7 \%$ & $1 \%$ \\
\hline HR & $12 \%$ & $8 \%$ & $1.5 \%$ \\
\hline RO & $11 \%$ & $3 \%$ & $1 \%$ \\
\hline BG & $21 \%$ & $10 \%$ & $0 \%$ \\
\hline
\end{tabular}

Source: Eurobarometer: Attitudes of Europeans Towards Tobacco, EC, 2006.

literature determining the effectiveness of various tobacco control policies have found the policies to be of varying effectiveness. For instance, while geographic smoking restrictions have been found generally effective (15), some advertising restrictions on tobacco products were found to be ineffective $(16,17)$.

The Croatian regulatory framework, however, is mostly determined somewhat exogenously by the process of joining the European Union (EU). It started in 2001 by signing the Stabilization and Association Agreement. One of the assignments within this process was to harmonize Croatia's legislation in compliance with the EU acquis communautaire. The ongoing process to make Croatian tobacco regulations compliant to the EU regulatory framework continued after Croatia became a candidate country in 2004 and after opening of the negotiations process for EU accession. Although major changes in the tobacco regulations in Croatia have been made, there are still outstanding harmonization issues regarding tobacco consumption and advertising.

In particular, the 1992 Croatian Food Safety Act banned the advertising of tobacco products in public places and in media. This was followed by a 1993 regulation requiring a tax stamp on each cigarette pack to monitor compliance and to control the

${ }^{4}$ It would be interesting to learn what percentage of the medicines were prescription versus non-prescription drugs. 
smuggling of cigarettes. New legislations considerably restricting tobacco consumption and advertising were introduced in Croatia in 1999. ${ }^{5}$ The law's provisions recognized smoking and passive smoking as harmful to health and forbade smoking in closed public areas. The maximum yield of tar per cigarette was limited to $12 \mathrm{mg}$. From 2005, more severe restrictions determined the yield of cigarettes not exceeding $10 \mathrm{mg}$ of tar per cigarette, $1 \mathrm{mg}$ of nicotine per cigarette and $10 \mathrm{mg}$ of carbon monoxide per cigarette. ${ }^{6}$ Advertising of tobacco products was banned and sales of tobacco products was forbidden to minors under the age of 18. The need for anti-smoking campaigns as well as their funding was also established by the law. From 2002 to 2003 a set of nationwide public campaigns were conducted to raise awareness about ill-health effects of tobacco use (18).

Compared to other transition countries, Croatia fares remarkably well as it imposes the maximum tobacco restrictions in each category: advertising restrictions, sales restrictions, geographic restrictions and health and packaging restrictions (14). The National Programme for the Integration of the Republic of Croatia into the EU for 2006 (19) also states that existing law is fully harmonized with the European Commission Directive 2003/23/EC on advertising and sponsorship of tobacco products. However, compared to the EU practice, there is more severe legislation envisaged to come in force in Croatia. The new law on the restricted use of tobacco products is expected to introduce mandatory health warnings and labeling, as they are already in force in the EU. The information on cigarette yields and mandatory health warnings should be placed more visibly. The product description suggesting that some trade- marks are less harmful to health is forbidden, such as cigarette brands marked "lights" or "mild". The new law was to come in force by the end of 2005 , then postponed to the end of 2006, with no official confirmation that it is in the legal procedure yet. Besides, there is obviously more room to improve current tobacco legislation, and then there is the outstanding issue of effective enforcement of existing regulations. The scope and effectiveness of these new regulations will only be realized in due course.

\section{Anti-smoking Advertising Effectiveness}

Advertising of tobacco products generates new smokers and induces current smokers to smoke more. Regulation of such advertising is driven by the negative health consequences of smoking and the fact that due to the habit forming nature of smoking, certain populations like the youth are especially vulnerable to cigarette advertising. Advertising regulations take many forms such as media bans (e.g., broadcast bans on cigarette advertising such as in the United States); restrictions on advertising content (whether to allow cartoon characters in advertising); and geographic advertising restrictions (bans on placement of cigarette billboards in the vicinity of schools).

Advertising bans are closely related complements to the antismoking campaigns. There is some evidence in the literature regarding the prevalence and effectiveness of anti-smoking programs at the aggregative level for some nations. Recent surveys of advertising bans have found that not all these bans are equally effective $(16,17)$.
Table 7. Effectiveness of anti - tobacco campaigns

\begin{tabular}{|l|c|c|}
\hline Country & $\begin{array}{c}\text { Smokers and ex-smokers } \\
\text { exposed to anti-smoking cam- } \\
\text { paigns }\end{array}$ & $\begin{array}{c}\text { Tobacco campaigns made } \\
\text { them want to quit smoking }\end{array}$ \\
\hline EU25 & $79 \%$ & $29 \%$ \\
\hline EU15 & $80 \%$ & $28 \%$ \\
\hline NMS10 & $77 \%$ & $29 \%$ \\
\hline CAC & $65 \%$ & $27 \%$ \\
\hline HR & $81 \%$ & $29 \%$ \\
\hline RO & $69 \%$ & $34 \%$ \\
\hline BG & $45 \%$ & $19 \%$ \\
\hline
\end{tabular}

Source: Eurobarometer: Attitudes of Europeans Towards Tobacco, EC, 2006.

The information in Table 7 provides unique insights at the micro level regarding the effectiveness of anti-smoking measures in European nations. Two aspects have been surveyed: the overall exposure to public campaigns and its impact to stop smoking. In both aspects, the anti-smoking campaigns seem equally effective in most nations, with the exception of Bulgaria. While in Bulgaria, only $45 \%$ of smokers and ex-smokers remember hearing about such campaigns, $81 \%$ of smokers and ex-smokers in Croatia were aware of public campaigns. That is an even higher percentage compared to the EU25 average of $79 \%$ and EU15 average of $80 \%$. Correspondingly, the share of target group of smokers and ex-smokers who upon being exposed to public campaigns have wanted to quit smoking was high. In Croatia $29 \%$ of smokers wanted to quit. The effectiveness of public campaigns in this respect was the highest in Romania where despite the rather low awareness of such campaigns (69\%), 34\% of those who had heard the campaigns were affected to want to stop smoking. Fewer smokers and ex-smokers in NMS10 were exposed to anti-tobacco campaigns than the EU15, suggesting perhaps a lack to resources devoted to such efforts. Croatia, however, fares remarkably well on that count.

\section{CONCLUDING REMARKS}

In recent years, tobacco use and its control have become increasingly the focus of attention of policy-makers and researchers due to ill health effects of smoking on both smokers and nonsmokers. Whereas our understanding of the use and regulation of tobacco products is quite good for a handful of nations (e.g., Australia, Canada, USA and UK), less is known about other nations including developing countries and nations in transition. This paper contributes to the neglected area by focusing on tobacco use and regulation in Croatia and its comparisons with its European counterparts.

In particular, this paper uses recent survey information to analyze the tobacco use patterns and regulation in Croatia. The focus of our research was to examine the smoking attitudes and influence of tobacco campaigns for Croatia in comparison to the EU candidate nations and the EU as a whole. Overall the results

${ }^{5}$ Law on restricted use of tobacco products, Official Gazette 128/99.

${ }^{6}$ Ordinance on safety requirements for general consumption items that may be released for free circulation, Official Gazette No. $42 / 04$. 
show that in some aspects of tobacco use and regulation Croatia fares better than other European countries, while in other aspects it is somewhat lagging. For instance, on the positive side, more Croat smokers and ex-smokers were exposed to anti-smoking campaigns than in other countries. Although there is evidence of high public exposure to the anti-tobacco public campaigns in Croatia (81\%), the effectiveness of such exposure is modest. The share of population that will stand up against second-hand smoke is also rather low. One possible explanation derived from the survey is that Croats seemed relatively more tolerant of other smokers (see Table 3).

On the other hand, Croatia has a relatively high incidence of smoking prevalence (36\%) and there are a largest proportion of heavy smokers of the surveyed European countries (3\% of smokers consume more than 35 cigarettes per day) and smokers who smoke at home $(87 \%)$. There is no evidence that cigarette consumption in Croatia is correlated with the use of other addictive products. On the other hand, the share of smokers in Croatia who never combine cigarette with an alcohol drink $(33 \%)$ is the lowest among the surveyed countries (Table 6). Based on this, policymakers can better direct tobacco control initiatives to specific areas of further raising anti-smoking awareness. Croatia also has to further strengthen the country's compliance with international tobacco control mandates in terms of enforcement of existing tobacco consumption restrictions. How quickly these deficiencies are "fixed" and what their marginal impact will be on the pace of Croatia's path to EU membership remains to be seen.

Finally, detailed data for enough time periods is needed before formal econometric studies of some these aspects can be conducted for Croatia and results compared to the extant literature. For instance, a widely held estimate of the price elasticity of cigarette demand is -0.4 , while more recent studies have shown the number to be somewhat higher $(15,20,21)$. However, it is yet not clear whether the corresponding elasticity for Croatia is greater than (or lower than) that number. In either case, such determination would have important implications for the design of effective tobacco excise tax policy in Croatia. Until that time, policy-makers and researchers will have to be content with data from the sources such as the ones presented in this paper and temper their recommendations accordingly.

\section{Acknowledgments}

Comments of two referees and Michael Nelson are appreciated. All remaining errors are our own.

\section{REFERENCES}

1. Jha P, Chaloupka FJ, Corrao M, Jacob B. Reducing the burden of smoking world-wide: effectiveness of interventions and their coverage. Drug Alcohol Rev. 2006 Nov; 25(6):597-609.

2. Jha P, Chaloupka FJ, editors. Tobacco control in developing countries. Oxford: Oxford University Press; 2000.
3. Jha P, Ranson MK, Nguyen SN, Yach D. Estimates of global and regional smoking prevalence in 1995, by age and sex. Am J Public Health. 2002 Jun;92(6):1002-6.

4. World Health Organization [homepage on the Internet]. Geneva: Framework Convention on Tobacco Control; 2003 May 21 [cited 2006 Nov 8]. Available from: http://www.who.int/mediacentre/news/releases/2003/ prwha1/en/print.html.

5. Attitudes of Europeans towards tobacco: special Eurobarometer 239 [monograph on the Internet]. Brussels: European Commission; 2006 [cited 2006 Nov 8]. Available from: http://ec.europa.eu/health/ph_information/documents/ebs 239 en.pdf.

6. WHO. Tobacco or health: a global status report. Geneva: WHO; 1997.

7. CDC [homepage on the Internet]. Atlanta: Centers for Disease Control and Prevention [cited 2006 Dec 20]. Global Health Professionals Survey: Croatia-Medical Students. Available from: http://www.cdc.gov/tobacco/ global/GHPS/factsheets/2005/euro/croatiamedical factsheet.htm.

8. CDC [homepage on the Internet]. Atlanta: Centers for Disease Control and Prevention [cited 2006 Dec 20]. Global Youth Tobacco Survey (GYTS) - Croatia. Available from: http://www.phppo.cdc.gov/tobacco/global/ GYTS/factsheets/euro/2002/croatia_factsheet.htm.

9. Goel RK, Morey MJ. The interdependence of cigarette and liquor demand. South Econ J. 1995 Oct;62(2):451-9.

10. Gruber J, Sen A, Stabile M. Estimating price elasticities when there is smuggling: the sensitivity of smoking to price in Canada. J Health Econ. 2003 Sep;22(5):821-42.

11. Zhao XY, Harris MN. Demand for marijuana, alcohol and tobacco: participation, levels of consumption and cross-equation correlations. Econ Rec. 2004 Dec;80(251):394-410.

12. Goel RK, Nelson MA. Tobacco policy and tobacco use: differences across tobacco types, gender and age. Appl Econ. 2005 Apr 20;37(7):765-71.

13. Ohsfeldt RL, Boyle RG, Capilouto E. Effects of tobacco excise taxes on the use of smokeless tobacco products in the USA. Health Econ. 1997 Sep-Oct;6(5):525-31.

14. Budak J, Goel RK, Nelson MA. Smoking prevalence and antismoking regulations in transition countries. Transit Stud Rev. 2006 May;13(1):23148.

15. Goel RK, Nelson MA. The effectiveness of anti-smoking legislation: a review. J Econ Surv. 2006 Jul;20(3):325-55.

16. Nelson JP. Cigarette advertising regulation: a meta-analysis. Int Rev Law Econ. 2006 Sep;26(2):195-226.

17. Saffer H, Chaloupka F. The effect of tobacco advertising bans on tobacco consumption. J Health Econ. 2000 Nov;19(6):1117-37.

18. Budak J, Lovrincevic Z. Tobacco economics in Croatia. In: Teodorovic I, editor. The Croatian economic development - transition towards the market economy. Zagreb: The Institute of Economics; 2005. p. 155-78.

19. Ministry of Foreign Affairs and European Integration the Republic of Croatia [homepage on the Internet]. Zagreb: National programme for the integration of Croatia into the European Union for 2006 [cited 2006 Nov 28]. Available from: http://www.mvpei.hr/ei/default.asp?ru=231\& $\mathrm{gl}=\&$ sid $=$ \&jezik=2.

20. Chaloupka FJ, Warner KE. The economics of smoking. In: Culyer AJ, Newhouse JP, editors. Handbook of health economics. Amsterdam: Elsevier; 2000. p. 1539-627.

21. Gallet CA, List JA. Cigarette demand: a meta-analysis of elasticities. Health Econ. 2003 Oct;12(10):821-35. 